\title{
Avaliação em educação ambiental: estudo de caso de um projeto em contexto de licenciamento
}

\author{
Luiza Maria Abreu de Mattos ${ }^{1}$ \\ Carlos Frederico Bernardo Loureiro ${ }^{2}$
}

Resumo: A avaliação é um dos princípios básicos da Educação Ambiental e, atualmente, uma de suas principais lacunas. Neste trabalho, realizamos um estudo de caso no qual analisamos os processos avaliativos instituídos em um projeto no âmbito do licenciamento de petróleo, o Projeto Pólen. A partir de uma abordagem baseada na Educação Ambiental Crítica e na educação no processo de gestão ambiental, observamos que projetos como o Pólen estão sendo concebidos de acordo com uma perspectiva crítica na qual os processos avaliativos buscam garantir espaços de participação e controle social e considerar os objetivos dos projetos relacionados à justiça ambiental. Todavia, esses processos ainda não se mostram satisfatórios, principalmente porque não são claramente planejados com esse intuito. Sendo assim, no seu decorrer, acabam praticamente se restringindo a verificar a eficiência da execução de suas etapas, centrando-se nos objetivos e na tomada de decisão por parte de seus coordenadores.

Palavras-chave: Educação ambiental. Avaliação. Projetos.

\section{Evalution in environmental education: a case study of a licensing-related project}

\begin{abstract}
Evaluation is one of the basic principles of Environmental Education and currently one of its main shortcomings. In this work we performed a case study in which we analyzed the evaluation process of an environmental project related to petroleum licensing, which is called Projeto Pólen. From an approach based on Critical Environmental Education and education for environmental management, we noticed that projects such as Pólen are being designed according to a critical perspective in which the evaluation process seeks to ensure areas for participation and social control and consider the goals related to environmental justice. However, these processes are not yet satisfactory, because they are not clearly planned with this purpose and therefore become restricted to evaluating the efficiency of the execution of their own stages, focusing on the established goals and the decision-making by their coordinators.
\end{abstract}

Keywords: Environmental education. Evaluation. Projects.

1 Pesquisadora do LIEAS / UFRJ. luizamattos@terra.com.br

2 Professor do PPGE e do EICOS / UFRJ. Líder do LIEAS / UFRJ. floureiro@openlink.com.br 


\section{Introdução}

De acordo com a maioria dos dicionários, avaliação pode ser definida como o ato de determinar ou estabelecer o valor de alguma coisa, examinar ou julgar. Para Worthen, Sanders e Fitzpatrick (2004), todas as abordagens da avaliação têm o mesmo objetivo comum, que é determinar o mérito ou valor de um programa ou parte dele. No entanto, a avaliação pode assumir diferentes papéis em diferentes contextos, no que se refere ao seu uso e a suas atividades essenciais (WORTHEN; SANDERS; FITZPATRICK, 2004).

No campo da Educação Ambiental, a avaliação é considerada um princípio, legitimado pelos seus principais documentos de referência nacionais e internacionais. Da Carta de Belgrado (1975) e Tbilisi (UNESCO-PNUMA, 1978) ao Tratado de Educação Ambiental para Sociedades Sustentáveis e Responsabilidade Global (1992) e às principais políticas públicas brasileiras de Educação Ambiental (BRASIL, 1999, 2005), todos os documentos fundadores da área reafirmam a avaliação como uma questão fundamental para o desenvolvimento de ações de Educação Ambiental.

No entanto, seja pela variedade de processos educativos no campo, seja pela abrangência de seus temas e objetivos, a maioria dos autores reconhece as dificuldades em avaliar e analisar de forma satisfatória as repercussões de suas atividades (TOMAZELLO; FERREIRA, 2001). Dessa maneira, a ausência de mecanismos de avaliação adequados é considerada, hoje, um dos principais obstáculos ao processo de desenvolvimento da Educação Ambiental (PLACEA, 2003). A ausência de dados e resultados concretos acerca dos programas e projetos realizados nos últimos anos é consequência dessa deficiência (VCIAEA, 2006) e contribui significativamente para o descrédito do campo (LAYRARGUES, 2000). Os escassos trabalhos publicados sobre o assunto, geralmente, tratam da inadequação dos instrumentos avaliativos tradicionais ou apontam uma enorme variedade de aspectos, sem discutir de forma aprofundada a concepção político-pedagógica da avaliação especificamente para a Educação Ambiental. Dessa forma, parece não se saber muito bem o que se quer nem o que se espera de um processo avaliativo satisfatório, embora se tenha clareza de sua relevância e das dificuldades no enfrentamento da questão.

\section{Objetivo e fundamentação teórico-metodológica}

Neste trabalho, buscamos avançar sobre esse tema realizando um estudo de caso no contexto da gestão ambiental pública, como parte do desenvolvimento de uma pesquisa de dissertação de mestrado (MATTOS, 2009). A partir de uma perspectiva crítica, analisamos os processos avaliativos instituídos em um projeto de Educação Ambiental no âmbito do licenciamento de atividades ligadas à exploração de petróleo offshore, o Projeto Pólen. A perspectiva adotada se baseia na Educação Ambiental Crítica, de acordo com Loureiro (2002, 2004a), e parte do entendimento de que a crise ambiental é indissociável do modelo social vigente e das desigualdades sociais decorrentes deste. Portanto, a educação deve 
ser entendida como elemento de transformação social através da emancipação dos sujeitos e da compreensão crítica da realidade, e a Educação Ambiental deve ter como principal objetivo promover a transformação das relações socioambientais atualmente estabelecidas, na busca por uma sociedade socialmente mais justa e ambientalmente equilibrada, fundada nos princípios de liberdade, igualdade, solidariedade, democracia, justiça social, responsabilidade e sustentabilidade (LOUREIRO, 2002).

A gestão ambiental pública é um processo social e institucional no qual os conflitos por usos e formas de apropriação dos recursos naturais se explicitam e no qual o Estado, sob controle social, possui o poder de legitimar interesses populares sob premissas públicas, em prol do bem-estar da população, de forma democrática e em favor da justiça social. Dessa forma, cabe à Educação Ambiental garantir que no processo de gestão os diferentes agentes sociais, prioritariamente os que se encontram na condição de expropriados e oprimidos, tenham condições efetivas de intervir nos processos decisórios sobre os recursos naturais enquanto bens comuns, diminuindo as assimetrias características do modelo social vigente (QUINTAS; GUALDA, 1995). A avaliação de projetos, nesse contexto, tem potencial para ser um espaço privilegiado para a participação popular no processo de gestão, pois permite a interferência direta da população nos projetos, durante sua execução.

Especialmente no licenciamento, a Educação Ambiental é vista como importante instrumento para a gestão ambiental democrática e participativa, principalmente pela capacidade de possibilitar que a população se aproprie do debate posto e possa atuar efetivamente nos espaços de decisão e participação existentes nesse processo (ANELLO, 2006). Assim, a Educação Ambiental pode influenciar positivamente as audiências públicas, a definição de medidas mitigadoras e compensatórias e o monitoramento subsequente à implantação dos empreendimentos licenciados (UEMA, 2006), cumprindo os propósitos da educação para a gestão (LAYRARGUES, 2000). De acordo com as bases legais relacionadas ao licenciamento ambiental - a Constituição Federal (BRASIL, 1988); a Política Nacional de Meio Ambiente (PNMA), Lei no 6.938, de 31 de agosto de 1981 (BRASIL, 1981); e a PNEA, Lei no 9.795, de 27 de abril de 1999 (BRASIL, 1999) -, os programas de Educação Ambiental integrados às atividades de licenciamento podem ser exigidos como medida compensatória e/ou mitigadora para a emissão de licenças ambientais. No entanto, muitas vezes esses programas utilizam metodologias que não consideram o processo de envolvimento e participação das comunidades em estado de vulnerabilidade socioambiental e não preveem espaços de avaliação adequados a esse propósito (ANELLO, 2006).

Nesse contexto, a Coordenação Geral de Petróleo e Gás (CGPEG) do Instituto Brasileiro do Meio Ambiente e dos Recursos Naturais e Renováveis (IBAMA) assumiu um papel pioneiro ao exigir que os programas de Educação Ambiental realizados como medidas mitigadoras e/ou compensatórias para a emissão de licenças ambientais no âmbito do licenciamento de petróleo efetivamente seguissem diretrizes que estivessem de acordo com a Política 
Nacional de Educação Ambiental (PNEA), principalmente no que se refere ao seu caráter crítico e participativo. A alta relevância econômica dos empreendimentos ligados ao petróleo coloca os projetos de Educação Ambiental gerados nesse cenário em uma situação privilegiada quanto à disponibilidade de recursos para sua realização.

Nesse contexto, o Projeto Pólen (Pólos Educativos do Norte Fluminense) surgiu através de uma exigência do IBAMA como medida compensatória para a emissão da licença ambiental para um empreendimento da Petróleo Brasileiro S.A. (Petrobras) que consiste na produção e escoamento de petróleo e gás natural do campo de Espadarte e da área leste do campo de Marimbá, Bacia de Campos (FPSO-Espadarte da Petrobras/UN-BC). O projeto está sendo executado pela Universidade Federal do Rio de Janeiro (UFRJ) desde 2005 e abrange os municípios de Saquarema, Araruama, Arraial do Cabo, Armação de Búzios, Cabo Frio, Casimiro de Abreu, Rio das Ostras, Macaé, Carapebus, Quissamã, Campos dos Goytacazes, São João da Barra e São Francisco de Itabapoana. O projeto inclui variadas ações de Educação Ambiental, como: capacitação de profissionais, principalmente técnicos das Secretarias Municipais de Educação e Meio Ambiente e lideranças locais; elaboração de material de apoio; e implementação de polos e projetos municipais de Educação Ambiental permanentes que serão, ao final do projeto, geridos pelos atores capacitados. Sendo assim, em função das características descritas, consideramos o Projeto Pólen um relevante e interessante caso de estudo e estabelecemos como nosso objetivo neste trabalho analisar os processos avaliativos nele instituídos pela UFRJ e pela Petrobras, enquanto realizadoras, e pelo órgão licenciador requerente, IBAMA.

Optamos pela metodologia do estudo de caso por ser uma modalidade de pesquisa pela qual se tenta entender fenômenos complexos em curto tempo, com base em questões do tipo "como?" e "por quê?" e foco em fenômenos contemporâneos, visando, com uma série de evidências, a generalização de pressupostos e conclusões por método indutivo (YIN, 2005), o que é adequado aos nossos objetivos de pesquisa. Utilizamos como instrumentos de pesquisa a análise documental de textos avaliativos produzidos no âmbito do projeto, como seu texto de origem, relatórios de acompanhamento, pareceres técnicos e entrevistas semiestruturadas com profissionais das instituições em questão envolvidos com a avaliação do projeto, como os professores da UFRJ coordenadores do Projeto Pólen, a profissional responsável pelo seu acompanhamento na Petrobras e os técnicos do IBAMA responsáveis pelo acompanhamento e monitoramento do projeto. A análise dos dados se baseou nos procedimentos estabelecidos por Minayo (2008), no que diz respeito à entrada no campo, aos registros e à interpretação de dados. Optamos pela realização de uma análise de conteúdo, na modalidade temática (MINAYO, 2008).

Os dados foram organizados de acordo com dois grupos de categorias: categorias teóricas pertencentes ao campo crítico da Educação Ambiental e categorias temáticas empíricas criadas a partir das análises preliminares dos dados 
e suas afinidades com as classificações comumente utilizadas no campo da avaliação.

No que diz respeito às categorias teóricas de análise, nos utilizamos de categorias que nos possibilitaram discutir e analisar os dados obtidos de forma coerente com nosso referencial. São elas: a práxis, a justiça ambiental, a autonomia, o controle social e a participação. Compreendemos a práxis enquanto atividade concreta através da qual os sujeitos se afirmam no mundo (KONDER, 1992); a justiça ambiental, enquanto conjunto de princípios universalistas de igualdade de direitos tanto na exposição aos riscos ambientais como no acesso aos benefícios trazidos pelos recursos (HERCULANO, 2002); a autonomia, como possibilidade de interferir na construção da própria presença no mundo, de forma livre das relações autoritárias (GADOT'TI, 1994); o controle social, enquanto controle da sociedade sobre o Estado (CARVALHO, 1996); e a participação, como compartilhamento do poder (LOUREIRO, 2004b).

As categorias temáticas empíricas utilizadas classificam os diferentes tipos de avaliação: formativa/somativa, interna/externa, objetivista/subjetivista, utilitarista/intuicionista/pluralista, quantitativa/qualitativa, centrada em objetivos/tomada de decisão/especialistas/participação (MINAYO; ASSIS; SOUZA, 2005; WORTHEN; SANDERS; FITZPATRICK, 2004). Assumimos que essas classificações compõem duas grandes tendências da avaliação: a avaliação normativa (objetivista/utilitarista/quantitativa) e a investigação avaliativa (subjetivista/intuicionista/pluralista/qualitativa).

A primeira se refere aos processos mais tradicionais de avaliação, que enfatizam a tecnologia, a medição e a comparação através da aplicação do método científico para investigar a efetividade dos programas, isolados de interferências do seu contexto. A avaliação é concebida como uma intervenção externa aos sujeitos e objetos avaliados (MINAYO; ASSIS; SOUZA, 2005), baseando-se em informações cientificamente reproduzíveis e verificáveis. Nesse caso, as estratégias adotadas tendem a seguir as abordagens utilitaristas, que determinam o valor de um programa a fim de beneficiar o maior número de pessoas possível, de acordo com critérios quantitativos (WORTHEN; SANDERS; FITZPATRICK, 2004).

Já o segundo bloco concebe a avaliação não como um evento isolado, mas como um processo, no qual o contexto é determinante e deve ser considerado (MINAYO; ASSIS; SOUZA, 2005). Nesse sentido, a avaliação deve integrar avaliadores e avaliados através de metodologias interativas que visam o aperfeiçoamento dos indivíduos, grupos, instituições e programas, e os critérios avaliativos devem ser elaborados de forma negociada e explícita (MINAYO; ASSIS; SOUZA, 2005). Considera-se que a validade da avaliação depende do avaliador, pois o valor atribuído ao projeto ou programa depende do impacto deste sobre cada indivíduo, de acordo com sentimentos e apreensões individuais e de grupos (WORTHEN; SANDERS; FITZPATRICK, 2004). Os indicadores utilizados nessa abordagem podem ser uma pluralidade de critérios e juízos que devem envolver como avaliadores todos os indivíduos ou grupos afetados pelo processo avaliado, enfatizando a descrição substantiva do avaliador e se 
concentrando nos processos sociais e nos significados dados pelos diferentes pontos de vista. Geralmente se empregam múltiplos métodos de coleta e se utiliza uma abordagem indutiva na análise dos dados (WORTHEN; SANDERS; FITZPATRICK, 2004).

\section{Resultados e conclusões}

Nossos resultados indicam que os processos avaliativos realizados no Projeto Pólen são bastante heterogêneos, incluindo reuniões internas e interinstitucionais, indicadores de metas, visitas de acompanhamentos, observações de campo, produção de relatórios, entre outros. Dessa forma, a avaliação inclui características de diferentes tendências normativas/objetivistas/ utilitaristas/quantitativas e subjetivistas/intuicionistas/pluralistas/qualitativas. Os processos ainda se centram nos objetivos, nos especialistas e na tomada de decisão por parte dos coordenadores do projeto, incluindo incipientes espaços de participação popular, como a formação de um conselho de acompanhamento que conta com a participação dos cursistas e avaliações pontuais em etapas específicas. No entanto, esses espaços ainda não possibilitam que a população envolvida exerça um poder real de decisão sobre o projeto, no sentido da autonomia.

As três instituições em questão demonstram basear a avaliação realizada nas diretrizes do IBAMA para projetos de Educação Ambiental no licenciamento de petróleo e nos princípios da educação para a gestão, que assumem uma perspectiva crítica alinhada às políticas públicas nacionais. Portanto, objetivam avaliar as transformações socioambientais geradas pelo projeto quanto à justiça ambiental e ao controle social. No entanto, na prática, de acordo com os próprios entrevistados, os processos realizados ainda não se mostram eficientes em avaliar se de fato o projeto foi capaz de contribuir para a mudança socioambiental da região, especialmente no que se refere à inclusão dos grupos atingidos pelos impactos nos processos decisórios relativos à sua mitigação.

No decorrer do projeto, se mostrou necessário incluir várias estratégias avaliativas complementares, em função da inadequação de determinados instrumentos previstos e da necessidade de se utilizar uma pluralidade de metodologias. Tanto nos documentos analisados quanto nas entrevistas com os responsáveis diretos por esse processo, a avaliação se mostrou bastante complexa, agregando diversos aspectos informais e subjetivos. A necessidade de adequação do processo avaliativo ao longo do desenvolvimento do projeto demonstra que a avaliação planejada na sua concepção não abrangia as necessidades reais. Dessa forma, a tentativa de aprimorar esse processo ao longo do seu desenvolvimento pode se mostrar bastante produtiva em alguns momentos, porém, há determinados aspectos da avaliação que não são passíveis de modificações ao longo do seu desenvolvimento.

A UFRJ, enquanto executora direta do projeto, possui uma riqueza de informações e visões sobre a avaliação do projeto incomparáveis e, por conta disso, pode ressaltar a importância de determinados instrumentos avaliativos 
com maior propriedade, principalmente daqueles relacionados à avaliação formativa, como é o caso das reuniões internas e das visitas de acompanhamento de campo. É importante destacar também a contribuição da UFRJ enquanto universidade pública autônoma que agrega produção de conhecimento, reflexões ideológicas e ainda possibilita a formação de recursos humanos dentro da perspectiva adotada.

Em relação à Petrobras, não há documentos avaliativos produzidos unicamente pela empresa. O principal documento utilizado são os relatórios semestrais produzidos pela UFRJ. Os parâmetros avaliativos se baseiam principalmente no cumprimento das exigências do IBAMA para a emissão da licença e em termos administrativos estabelecidos no convênio entre Petrobras e UFRJ. Há, por parte dos consultores entrevistados, um sério comprometimento com e apropriação dos princípios estabelecidos pelas diretrizes do IBAMA como critérios avaliativos, embora ainda possa haver espaço para interpretações burocráticas dessas exigências, por parte de outros consultores.

Em relação ao IBAMA, a avaliação se baseia principalmente na linha da educação no processo de gestão ambiental, a partir da qual foram criadas as diretrizes para programas de Educação Ambiental no licenciamento de petróleo (IBAMA, 2005). Nesse sentido, os processos avaliativos possuem documentos balizadores dentro de uma linha crítica, porém, estão sujeitos a variações metodológicas de acordo com as interpretações subjetivas dos técnicos envolvidos, visto que os instrumentos avaliativos formalmente previstos se restringem à avaliação dos relatórios semestrais da equipe executora. Atualmente, há uma tendência em investir cada vez mais no acompanhamento dos projetos, principalmente no campo, a fim de contribuir com avaliações formativas ao longo de sua execução e de formalizar um contato direto com a população para a qual o projeto se destina. Não há nenhum espaço formal de participação popular na avaliação do projeto realizada pelo IBAMA, embora suas colocações sejam informalmente consideradas pelos entrevistados. É importante ressaltarmos que dentro do próprio órgão há claramente um pioneirismo por parte da coordenação de petróleo e gás com relação à importância atribuída aos projetos de Educação Ambiental e que esse movimento ainda não se estende ao IBAMA como um todo nem a todas as coordenações de licenciamento.

Outro resultado importante diz respeito à grande influência do pioneirismo do Projeto Pólen nos seus processos avaliativos, tanto no que se refere à intenção de se realizar um projeto e uma avaliação efetivamente baseados em princípios críticos da Educação Ambiental de acordo com a PNEA (BRASIL, 1999) quanto em relação às dificuldades decorrentes do ineditismo dessa iniciativa. As três instituições em questão, IBAMA, Petrobras e UFRJ, possuem comprometimento, mesmo que em medidas distintas, com os princípios críticos da educação no processo de gestão ambiental enquanto norteadores do Projeto Pólen e de sua avaliação, o que parece ser algo ainda incomum no contexto da gestão pública. É importante ressaltarmos que esse processo foi inicialmente impulsionado pelo IBAMA, que, enquanto órgão ambiental regulador, exigiu que o projeto estivesse de acordo com as políticas públicas nacionais de Educação 
Ambiental. No entanto, as três instituições apresentam dificuldades nesse sentido, em grande parte porque as questões problemáticas só são percebidas no decorrer do desenvolvimento do projeto, já que não há experiências anteriores nas quais possam se espelhar.

Nossas principais conclusões indicam que no contexto do licenciamento e na gestão ambiental pública há projetos, como o Projeto Pólen, que vêm sendo concebidos de acordo com uma perspectiva crítica e cujos processos avaliativos buscam relacionar os objetivos propostos à transformação e à justiça ambiental, tendo em conta a importância de espaços de participação e controle social. No entanto, na prática esses processos ainda não se mostram satisfatórios, pois as estratégias avaliativas utilizadas não permitem avaliar claramente as transformações socioambientais ocorridas em função dos projetos e não há ainda espaços efetivos de controle social e participação popular com autonomia no processo avaliativo. Parece haver sérias dificuldades em se prever a complexidade do processo avaliativo no momento da concepção do projeto, e, ao longo do seu desenvolvimento, com todas as demandas relacionadas à sua execução, esse processo acaba se voltando unicamente para os objetivos e a tomada de decisão por parte de seus coordenadores, verificando apenas a eficiência na execução dos projetos, mesmo que, originalmente, essa não fosse a intenção.

Sugerimos, então, que uma forma de avançar na questão da avaliação nesse contexto seria planejar os processos avaliativos desde a origem dos projetos com o intuito de avaliar não só sua execução mas também sua contribuição para as transformações da região no tocante à justiça ambiental. Para tanto, é preciso utilizar variados instrumentos avaliativos com esses objetivos, os quais devem estar de acordo com a concepção político-pedagógica do projeto. Uma iniciativa baseada em uma linha crítica, para se manter coerente com essa concepção, deve criar espaços de participação popular e controle social dentro do próprio projeto e através da práxis ajudar na construção de uma cultura democrática (MATTOS, 2009).

Outros autores que trabalharam com o tema da avaliação em Educação Ambiental, como Depresbiteris (2001) e Tomazello (2001), também concluíram que as formas de avaliação tradicionais não se adéquam à Educação Ambiental e que os resultados das ações de Educação Ambiental dificilmente têm uma relação direta com uma única atividade que possa ser avaliada de forma isolada e independente. Portanto, a avaliação desses processos não pode se restringir somente a uma perspectiva de análise, deve levar em conta diversos aspectos da realidade e recorrer a diversas dimensões do conhecimento (DESPRESBITERIS, 2001). Em uma perspectiva crítica, sugerimos que se explore mais o uso de instrumentos provenientes das Ciências Sociais na formulação de indicadores relacionados aos aspectos socioambientais, visto que esses instrumentos parecem ser deficientes na Educação Ambiental tradicional, baseada em aspectos provenientes da Ecologia/Biologia e da Educação. Índices de renda, de mobilização social e de participação popular nos processos decisórios poderiam contribuir para os processos avaliativos em questão, de acordo com a perspectiva adotada. Outro instrumento que pode vir a auxiliar 
esse tipo de avaliação são os diagnósticos socioambientais, comumente utilizados em projetos de Educação Ambiental. No entanto, para que se prestem ao fim avaliativo, esses diagnósticos precisam ser pensados e executados desde o início do projeto como estratégias avaliativas.

Por meio das reflexões e considerações que desenvolvemos com base nos dados obtidos na nossa pesquisa, esperamos ter contribuído para o avanço das questões relacionadas à problemática lacuna que é a avaliação de projetos de Educação Ambiental.

\section{Referências}

ANELLO, Lucia de Fatima Socoowski de. Pensando e praticando a Educação Ambiental no Licenciamento: o sistema Portuário do Rio Grande. Brasília: IBAMA, 2006. 97 p. (v. 1).

BRASIL. Lei no. 6.938, de 31 de agosto de 1981. Política Nacional de Meio Ambiente (PNMA). 1981. Disponível em: <http://www.planalto.gov.br/ccivil_03/Leis/

L6938.htm>. Acesso em: 14 out. 2008.

. Constituição da República Federativa do Brasil: promulgada em 5 de outubro de 1988; atualizada até a Emenda Constitucional no 20, de 15 de dezembro de 1988. Brasília: Senado, 1988. Disponível em: <http://www.lei.adv.br/225-88.htm>. Acesso em: 11 set. 2008.

. Lei $n^{\circ}$. 9.795, de 27 de abril de 1999. Política Nacional de Educação Ambiental (PNEA). 1999. Disponível em: <www.planalto.gov.br/ccivil_03/leis/19795.htm>. Acesso em: 25 ago. 2008.

- Programa Nacional de Educação Ambiental. Ministério do Meio Ambiente, Diretoria de Educação Ambiental; Ministério da Educação, Coordenação Geral de Educação Ambiental. 3 ed. Brasília: MMA, 2005. Disponível em:

<http://portal.mec.gov.br/secad/arquivos/pdf/educacaoambiental/pronea3.pdf $>$. Acesso em: 14 out. 2008.

CARTA de Belgrado. 1975. Disponível em:

<http://www.ufpa.br/npadc/gpeea/DocsEA/A\%20Carta\%20de\%20Belgrado.pdf>. Acesso em: 5 jun. 2008.

CARVALHO, Antônio Ivo. Controle social: aparato regulatório e práticas emancipatórias. In: CONFERÊNCIA MUNICIPAL DE SAÚDE DE BH, 5., 1996, Belo Horizonte. Caderno de textos... Belo Horizonte: 1996.

DEPRESBITERIS, Léa. Avaliação da Aprendizagem na Educação Ambiental: uma relação muito delicada. In: SATO, Michèle; SANTOS, José Eduardo dos (Org.). A Contribuição da Educação Ambiental à Esperança de Pandora. São Carlos: RIMA, 2001. p. 531557.

GADOTTI, Moacir. A autonomia como estratégia da qualidade de ensino e a nova organização do trabalho na escola. Trabalho apresentado no $2^{\circ}$ Seminário Nacional Escola Cidadã, Porto Alegre, mar. 1994. 
HERCULANO, Selene. Riscos e desigualdade social: a temática da Justiça Ambiental e sua construção no Brasil. In: ENCONTRO DA ASSOCIAÇÃO NACIONAL DE PÓSGRADUAÇÃO E PESQUISA EM AMBIENTE E SOCIEDADE, 2002, Indaiatuba. Anais... Indaiatuba, São Paulo: ANPPAS, 2002.

INSTITUTO BRASILEIRO DO MEIO AMBIENTE E DOS RECURSOS NATURAIS E RENOVÁVEIS (IBAMA). Coordenação Geral de Educação Ambiental. Orientações Pedagógicas do IB AMA para Elaboração e Implementação de Programas de Educação Ambiental no Licenciamento de Atividades de Produção e Escoamento de Petróleo e Gás natural. Anexo ao Termo de Referência para Licenciamento Ambiental das Atividades de Produção e Escoamento de Petróleo e Gás Natural. Brasília: 2005.

KONDER, Leandro. O futuro da filosofia da práxis. Rio de Janeiro: Paz e Terra, 1992.

LAYRARGUES, Philippe Pomier. Educação para a gestão ambiental: a cidadania no enfrentamento político dos conflitos socioambientais. In: LAYRARGUES, Philippe Pomier; LOUREIRO, Carlos Frederico Bernardo; CASTRO, Ronaldo Souza de (Org.).

Sociedade e Meio Ambiente: a educação ambiental em debate. São Paulo: Cortez, 2000. p. 87155. v. 1. Disponível em: <http://material.nerea-

investiga.org/publicacoes/user_35/FICH_PT_30.pdf>. Acesso em: 20 ago. 2008.

LOUREIRO, Carlos Frederico Bernardo. Educação Ambiental Crítica: Princípios Teóricos e Metodológicos. Rio de Janeiro: Hotbook, 2002. 66 p. v. 1. Disponível em: <http://www.zinzaswebsite.hpg.com.br/Z13/Kids/AZ/E.5/E.Ambiental.pdf>. Acesso em: 3 maio 2006.

. Trajetória e fundamentos da Educação Ambiental. São Paulo: Cortez, 2004a.

. Educar, Participar e Transformar em Educação Ambiental. Revista Brasileira de Educação Ambiental, Brasília, v. 01, n. 00, p. 13-20, 2004b. Disponível em:

<http://www.ufmt.br/remtea/revbea/pub/revbea_n_zero.pdf\#page=13>. Acesso em: 23 jul. 2008.

MATTOS, Luiza Maria Abreu de. A Avaliação de ações de Educação Ambiental: um estudo exploratório no âmbito da gestão pública sob uma perspectiva crítica. 2009. Dissertação (Mestrado em Psicossociologia de Comunidades e Ecologia Social) - EICOS, Instituto de Psicologia, Universidade Federal do Rio de Janeiro, Rio de Janeiro, 2009.

MINAYO, Maria Cecília de Souza (Org.). Pesquisa social: teoria, método e criatividade. 27. ed. Rio de Janeiro: Vozes, 2008.

MINAYO, Maria Cecília de Souza; ASSIS, Simone Gonçalves de; SOUZA, Edinilsa Ramos de (Org.). Avaliação por triangulação de métodos: abordagem de programas sociais. Rio de Janeiro: Fiocruz, 2005.

PLACEA. Proposta de Programa Latino-americano e Caribenho de Educação Ambiental no Marco do Desenvolvimento Sustentável. 2003. Resumo Executivo. Disponível em: <www.reasul.org.br/mambo/files/placea_resexec.pdf>. Acesso em: 16 jul. 2008.

QUINTAS, José Silva; GUALDA, Maria José. A formação do Educador para atuar no Processo de gestão Ambiental. In: SEMINÁRIO SOBRE A FORMAÇÃO DO EDUCADOR PARA ATUAR NO PROCESSO DE GESTÃO AMBIENTAL, 1995, Brasília. Anais... Brasília: Instituto Brasileiro do Meio Ambiente e dos Recursos Naturais Renováveis, 1995. Disponível em: 
<http://www.ibama.gov.br/edicoes/site/paginas/pubSeriadasMeioAmbiente.htm>. Acesso em: dez. 2007.

TRATADO de Educação Ambiental para Sociedades Sustentáveis e Responsabilidade Global. 1992. Disponível em:

$<$ portal.mec.gov.br/secad/index2.php?option=com_content\&do_pdf=1\&id=76 ->. Acesso em: 21 jun. 2008.

TOMAZELLO, Maria Guiomar Carneiro; FERREIRA, Tereza Raquel das Chagas Educação Ambiental: que critérios adotar para avaliar a adequação pedagógica de seus projetos? Ciência \& Educação, v. 7, n. 2, p. 199-207, 2001. Disponível em:

<http://www.rebea.org.br/acoes/tecendo/ponto_008.pdf>. Acesso em: jun. 2006.

UEMA, Elisabeth Eriko. Controle social e participação no licenciamento. Brasília: IBAMA, 2006.

UNESCO-PNUMA. Declaração e Recomendações da Conferência Internacional de Tbilisi-1977. Relatório Final da Conferência de Tbilisi, Tibilisi, URSS. 1978.

VCIAEA. Extrato analítico do Grupo de Trabalho "Educação Ambiental e avaliação" sob a coordenação de Alexandre Pedrini, Liana Justen e Javier García Gómez e relatoria de Catia Hansel. In: CONGRESSO IBERO-AMERICANO DE EDUCAÇÃO AMBIENTAL, 5., 2006, Joinville. Disponível em:

<http://www.5iberoea.org.br/html/edu_avaliacao.html>. Acesso em: out. 2008.

WORTHEN, Blaine R.; SANDERS, James R.; FITZPATRICK, Jody L. Avaliação de programas: concepções e práticas. Tradução de Dinah de Abreu Azevedo. São Paulo: Gente, 2004.

YIN, Robert K. Estudo de Caso: planejamento e método. Porto Alegre: Bookman, 2005. 